\title{
Quantification of Lupeol as Secondary Metabolite by HPTLC Technique and Assessment of Antimicrobial Potential of Ethyl Acetate Extract of Betula alnoides Bark
}

\author{
SHAHBAZ KHAN ${ }^{1 *}$, HARPREET SINGH ${ }^{2}$, ARUN K MISHRA ${ }^{1}$ and NAJAM ALI KHAN ${ }^{2}$
}

${ }^{1}$ Pharmacy Academy, IFTM University, Moradabad, 244102, India.

${ }^{2}$ School of Pharmaceutical Sciences, IFTM University, Moradabad, 244102, India.

${ }^{*}$ Corresponding author E-mail: shahbazkhan1792@ yahoo.com

http://dx.doi.org/10.13005/ojc/370223

(Received: February 23, 2021; Accepted: April 06, 2021)

\begin{abstract}
The present work includes extraction of Betula alnoides bark using ethyl acetate as a solvent, preliminary phytochemical test, quantification of phytochemicals and quantification of lupeol in Betula alnoides by High Performance Thin Layer Chromatography (HPTLC) instrument along with the assessment of the antimicrobial potential of Ethyl Acetate Extract (EAE). The marc obtained after defatting of the coarsely powdered crude drug in Petroleum ether (60-80) was extracted using ethyl acetate. Afterward, preliminary phytochemical tests were done. For High Performance Thin Layer Chromatography (HPTLC), the solvent used was $n$-hexane: ethyl acetate $(8: 2 \mathrm{v} / \mathrm{v})$ and scanning was performed at wavelength $254 \mathrm{~nm}$. EAE was screened for antimicrobial potential. The extraction yield was $3.45 \% \mathrm{w} / \mathrm{w}$. The result of the phytochemical analysis confirmed the presence of some important phytochemicals in EAE. A clear and resolved peak of lupeol was observed at $R_{f} 0.61$. The developed method was validated as per ICH guidelines. The concentration (\%) of the marker compound (lupeol) was found to be 0.0168 . Disk diffusion method using Staphylococcus aureus, Pseudomonas aeruginosa and Bacillus subtilis as bacterial strains and Candida albicans, Aspergillus flavus and Epidermophyton floccosum as fungal strains against ciprofloxacin (for antibacterial activity) and fluconazole (for antifungal activity) as standard drugs was employed. The finding suggested that EAE possess significant antibacterial and antifungal activity when comparison was made with standard drugs. The proposed elucidated mechanism behind this action may be due to the presence of triterpenoids in Ethyl Acetate Extract.
\end{abstract}

Keywords: Betula alnoides, Lupeol, Ethyl Acetate Extract, Antimicrobial, HPTLC quantification.

\section{INTRODUCTION}

The herbs containing active ingredients are used for the treatment of various ailments ${ }^{1}$. Herbs are used traditionally in numerous medicinal system due to their proven beneficial effects on humans ${ }^{2}$.
About 70 to $90 \%$ of humans still rely on traditional remedies to treat the common and uncommon diseases $^{3}$. In the presentera, herbal medicines are more preferred over synthetic medicine due to increased side effects of synthetic medicine. The literature available on herbal medicine suggest

This is an Open Access article licensed under a Creative Commons license: Attribution 4.0 International (CC- BY). Published by Oriental Scientific Publishing Company @ 2018

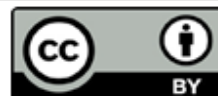


that there are number of herbs which have enough potential to inhibit bacterial growth.

Among various commonly used medicinal trees, Betula alnoides is commonly used and a choice of preference to treat various ailments. Betula alnoides (family Betulaceae) is an indigenous medicinal plant known as Indian birch. The genus Betula comprises more than 35 scientifically recognized species out of which Betula alnoides is geographically indigenous to the Himalayan region of India and is also found in Myanmar, Thailand and Southern China ${ }^{4}$. In the traditional system of medicine, the bark of this plant is used as anthelmintic, epileptic, anti-inflammatory, antioxidant, antimicrobial, heart stimulant, carminativum and antipyretic (Fig. 1). The paste of the bark of the Betula alnoides is also used traditionally to heal numerous skin problems. It is a decorative tree with attractive cluster of small flowers. Inflorescences are having two/three flowering cymes. In India, Betula alnoides is used traditionally to treat microfractures, after birth pain, pain in joints and ligament tearing. Various phytochemical constituents which has been reported in Betula alnoides includes quercetin, taraxeryl acetate, oleanolic acid, betulin, betulinic acid and taraxerone etc. Betula alnoides can be cultivated easily on the land with little agricultural value $e^{5,6,7,8,9}$.

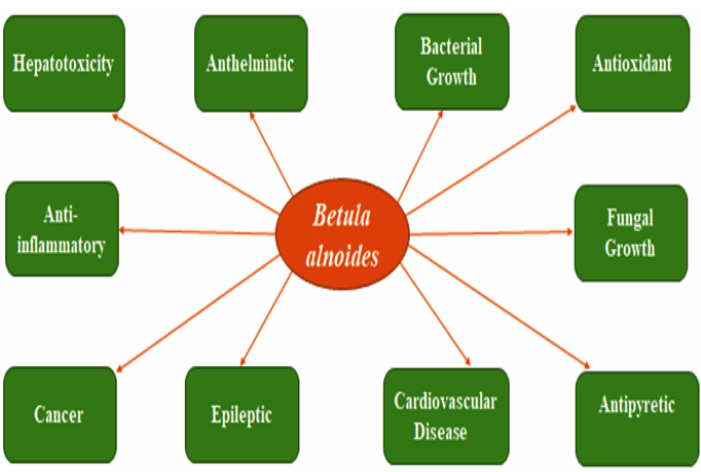

Fig. 1. Different pharmacological activities of Betula alnoides bark

In order to identify the phytochemicals qualitatively and quantitatively, analytical techniques including HPTLC is employed commonly ${ }^{10}$. HPTLC is one of the accurate techniques for the development of fingerprint and marker-based drug standardization ${ }^{11}$. HPTLC technique is generally used for identification, purity testing, stability and content uniformity of herbs and their formulations ${ }^{12}$. Lupeol is one of important phytoconstituent which is of great importance to inhibit the bacterial and fungal growth. Therefore, keeping in view this fact that lupeol as important phytoconstituents of Betula alnoides, HPTLC method was developed, validated and then quantified. The literature review concludes that till date antimicrobial activity has not been explore till date scientifically. Therefore, emphasis was laid to screen their unimportant activity of Betula alnoides.

\section{MATERIALS AND METHODS \\ Plant Collection and Authentication}

Betula alnoides bark was collected from the mountains of the village, Chitkul (a village in Kinnaur district of Himachal Pradesh), India. The authentication of the plant part was performed by Scientist in charge, NISCAIR, Delhi vide reference number NISCAR/ RHMD/Consult/2019/3529-30. The authentication specimen is preserved for further reference.

\section{Chemical and Solvents}

Analytical-grade chemicals and solvents were used. Chemicals and standard drugs (Ciprofloxacin and Fluconazole) were procured from $\mathrm{CDH}(\mathrm{P})$ Ltd., Delhi, India. Lupeol as the reference standard (Purity: 99.91\%) was availed from SigmaCo., USA. Ciprofloxacin and Fluconazole, were purchased from $\mathrm{CDH}(\mathrm{P})$ Ltd., Delhi, India.

\section{Plant Extraction}

After the collection of bark, it was first dried in shade for two days and then cut into smaller pieces, crushed to coarse powder. After defatting in petroleum ether (60-80), it was further subjected to extraction in ethyl acetate. Extraction was done in Soxhlet apparatus ${ }^{13}$. The extract was dried using the vacuum-dryer. Extraction yield and other physical parameters are presented in Table 1.

\section{Screening of Phyto-chemicals}

Experimental autoimmune encephalomyelitis was subjected to phyto-chemical tests with an aim to identify the secondary metabolites present in $\mathrm{EAE}$ using standard procedures ${ }^{14}$.

\section{Quantitative Estimation of Phytochemicals}

Quantitative estimation of phytochemicals was done to estimate the amount of various phytoconstituents using standard procedures ${ }^{14}$.

\section{HPTLC Analysis}

Standard stock solution of lupeol was 
prepared by dissolving lupeol $(3 \mathrm{mg}$ ) in $25 \mathrm{~mL}$ ethyl acetate in a volumetric flask. In order to obtain the line equation and standard curve, the lupeol (1-10 ul) concentrated sample was marked on already prepared TLC plates. Dried EAE was added in $10 \mathrm{~mL}$ ethyl acetate and $20 \mu$ solution of EAE was placed on TLC plate. Silica gel plates were employed in the present study. The solvent $n$-hexane and ethyl acetate in the ratio of 8:2 were used as mobile phase. The plates were treated with $10 \mathrm{~mL}$ stannous chloride in chloroform $(40 \mathrm{~mL})$ and glacial acetic acid $(40 \mathrm{~mL})$. UV-light was used for the observation of TLC plates. Reddish-brown fluorescence was observed.

HPTLC plate $(20 \mathrm{~cm} \times 10 \mathrm{~cm}$ consists glass supported) precoated by Silica gel G (60F254) plates was employed in the present investigation. The Linomat $V$ autosampler (Camag) was used for spotting purpose. A Microsyringe of $100 \mu$ capacity (Hamilton) and WinCAT software was used in the present analytical study. Two-hour time was used for saturation of the mobile phase tank. EAE was applied on the TLC plate and the plate was developed in $n$-hexane: ethyl acetate $(8: 2 \mathrm{v} / \mathrm{v})$. Drying of plates was performed in the air. The plates were scanned at $254 \mathrm{~nm}$. The $R_{\mathrm{f}}$ values were recorded.

\section{Method Validation}

In order to validate the developed method, $\mathrm{ICH}$ guidelines were followed (ICH 2005). A graph was plotted between peak area versus amount applied. The calibration curve for lupeol was obtained. $\mathrm{ICH}$ guidelines were followed to determine LOD and LOQ. By repeated analysis of lupeol, interday and intraday precision study was also performed.

\section{Microorganisms}

Bacterial strains including Staphylococcus aureus [ATCC 25923 (Gram-positive)], Pseudomonas aeruginosa [ATCC 27 (Gram-negative)] and Bacillus subtilis [MTCC 441 (Gram-positive)] were employed for antibacterial activity. Fungal strains like Aspergillus flavus [MTCC 1344], Candida albicans [MTCC 227] and Epidermophyton floccosum 73/01 were employed for antifungal activity.

\section{Antimicrobial Activity of EAE}

Employing the disc diffusion method, antibacterial activity was screened. In this method, the Petri plates were made ready for an experimental procedure using $20 \mathrm{~mL}$ of sterile
MHA (Mueller-Hilton Agar) for bacterial strains and $20 \mathrm{~mL}$ of Sabouraud Dextrose Agar (SDA) for fungal strains. For the determination of zone of inhibition (ZOI), ciprofloxacin (antibacterial) and fluconazole (antifungal) were used as standards. The $100 \mu \mathrm{l}$ of log cultures of all the bacteria (adjusted to 1 MacFarland Unit) were spread using inoculum on sterile MHA plates and then by placing the discs having $10 \mu \mathrm{l}$ of different dilutions with concentration $(50-1000 \mu \mathrm{g} / \mathrm{mL})$. The disc was loaded with $10 \mu \mathrm{l}$ of solvent (in physiological buffer solution) in a way that extract can diffuse the medium. The single disc was loaded with the only solvent which was marked as vehicle control and a ciprofloxacin disc $(30 \mu \mathrm{g})$ was marked as a positive control. Incubation was done at $37^{\circ} \mathrm{C}, 24$ $\mathrm{h}$ for bacterial strains. For fungal strains, $48 \mathrm{~h}$ at $27^{\circ} \mathrm{C}$ temp was used. Zones created around the discs were recorded in millimeters. Antibacterial activity was assessed by measuring the diameter of ZOI around the discs. Assay was repeated thrice. Antibacterial activity was expressed as the mean ZOI diameters $(\mathrm{mm})$ produced by the Experimental autoimmune encephalomyelitis ${ }^{15}$.

\section{Minimum Inhibitory Concentrations (MIC) and Minimum Bactericidal Concentrations (MBC) of $\mathrm{EAE}^{16}$}

Minimum Inhibitory Concentrations is expressed as the minimum concentration of active ingredient, which prevent the growth of microbes after $24 \mathrm{~h}$ of incubation. Various concentrations of the EAE used (50, 100, 250, 500 and $1000 \mu \mathrm{g} /$ $\mathrm{mL}$ ) were loaded on sterilized filter paper discs of diameter $8 \mathrm{~mm}$. MHA medium was added to sterile petri plates, then cultured through suspensions of bacterial strains. On the top surface of MHA plates, EAE in different concentration on filter paper disc was kept. MHA plates were kept in the refrigerator at $5^{\circ} \mathrm{C}$ for time period of 2 hours. Afterward, incubation was done at $35^{\circ} \mathrm{C}$ for 24 hours. The $\mathrm{ZOI}$ was noted for EAE concentration.

Streaks were considered from the two lowest concentrations of the EAE plates, having nonvisible growth and subculturing was done on sterile plates. Tryptone soya agar-based plate were 
used for subculturing. The Tryptone soya agar-based plates were subjected to incubation at $35^{\circ} \mathrm{C}$ for 24 $\mathrm{h}$ and further observed for the growth of bacteria in comparison with concentration of EAE. MBC for EAE is considered as concentration of extract on which, bacterial growth is not exhibited ${ }^{17}$.

\section{RESULT AND DISCUSSION}

\section{Extraction Yield}

The extraction of bark was done in ethyl acetate after defatting in petroleum ether $\left(60-80^{\circ} \mathrm{C}\right)$. The extraction yield and physical parameters are presented in Table 1.

Table 1: Extraction yield and physical parameters of Betula alnoides bark extract

\begin{tabular}{ccccc}
\hline S. no. & Solvent & Extraction yield $(\% \mathrm{w} / \mathrm{w})$ & Color & Physical Appearance \\
\hline 1 & Ethyl acetate & $3.45 \pm 0.21$ & Light cream & Coarse powder \\
\hline
\end{tabular}

\section{Preliminary Phytochemical Screening}

Standard procedure was employed to screen the presence of phytochemicals. The preliminary screening of phytochemicals confirmed the presence of triterpenoids, flavonoids, saponin, proteins and carbohydrates in the Experimental autoimmune encephalomyelitis.

\section{Quantification of Secondary Metabolites}

The observation of phyto-chemicals quantification confirmed the availability of triterpenoid in the highest concentration in EAE (Table 2). The alkaloids were nil however next least concentration of saponins was observed.

Table 2: Quantification of secondary metabolites in EAE

\begin{tabular}{cc}
\hline Secondary Metabolites & Quantity $(\mathrm{mg} / 100 \mathrm{~g})$ \\
\hline Alkaloids & - \\
Saponins & $5.44 \pm 0.42$ \\
Carbohydrates & $6.37 \pm 0.22$ \\
Triterpenoid & $20.65 \pm 0.04$ \\
\hline
\end{tabular}

\section{Quantification by HPTLC Densitometry}

The current work is the first report of quantification of lupeol by HPTLC study in Betula alnoides. The HPTLC densitometric chromatogram of lupeol in EAE is presented in Fig. 2 and Fig. 3. The peaks resolving at $R_{f} 0.61$ in the test solution were found to be superimposable with the bands obtained for lupeol as standards.

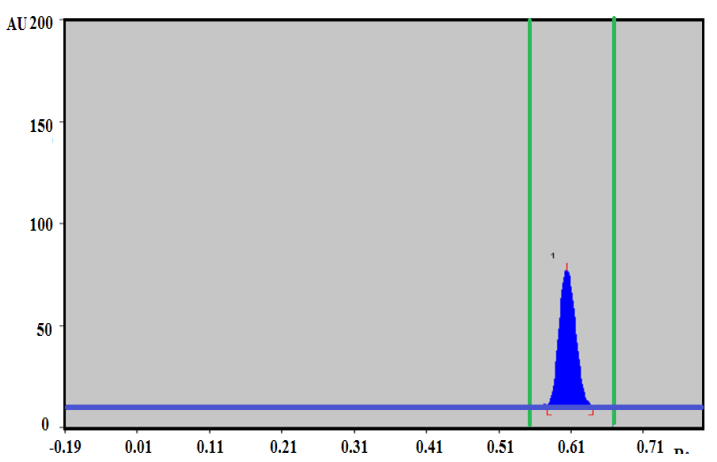

Fig. 2. HPTLC densitometric chromatogram of reference standards Lupeol (at $254 \mathrm{~nm}$ )

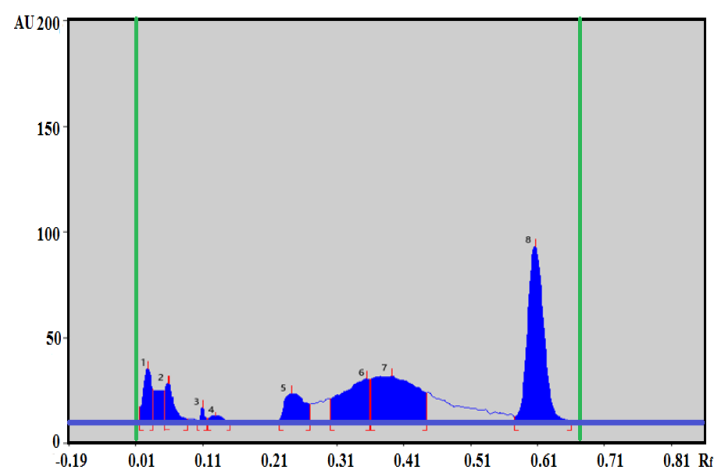

Fig. 3. HPTLC densitometric chromatogram of EAE of Betula alnoides bark scanned at $254 \mathrm{~nm}$

The calibration curve was draw using different concentrations of lupeol reference standard and a line equation was established. The calibration curve drawn was linear in the range of 200-1000 ng. The correlation coefficient for the line equation was found to be 0.9981 Table 3 .

Relative Standard Deviation (RSD) was found to be in the range of $0.342-0.874 \%$ for lupeol. The interday and intraday precision study was performed. The findings suggested that method is précised.

The study revealed that LOD and LOQ were 32.69 and $101.33 \mathrm{ng} / \mathrm{spot}$ for lupeol. $\%$ Recovery of lupeol was found to be in the range of $98.38 \pm 0.22$, which exhibited the reproducibility and acceptability of the method. The outcome of the method validation parameter study is presented in Table 3, 4, 5 and 6. The method validation study was done in triplicate and it was found to be reliable, accurate and appropriate. Therefore, the current HPTLC method is proved as an easy, fast and accurate method for lupeol quantification from the bark of Betula alnoides. 
Table 3: Method validation parameter

\begin{tabular}{lccccc}
\hline Compound & Regression equation & Correlation coefficient $\left(R^{2}\right)$ & Linear range ng/spot & LOD (ng/spot) & LOQ (ng/spot) \\
\hline Lupeol & $y=2.345 x+301.8$ & 0.9981 & $200-1000$ & 32.69 \\
\hline
\end{tabular}

Table 4: Intraday and interday precisions $(n=6)$

\begin{tabular}{lccc}
\hline Compound & Concentration(ng/band) & Intra-day RSD for peak area (\%) & Inter-day RSD for peak area (\%) \\
\hline Lupeol & 200 & 0.566 & 0.674 \\
& 400 & 0.874 & 0.580 \\
600 & 0.342 & 0.887 \\
\hline
\end{tabular}

Table 5: Accuracy study (\% recovery) of Lupeol ( $n=3)$

Compound Extract \% Recovery (average of three replicates) \pm SEM

Lupeol $\quad$ EAE $\quad 98.38 \pm 0.22$

The content of lupeol in the bark of Betula alnoides was calculated on the basis of area of the peak. The content was found to be $0.0168 \%$ in $\mathrm{EAE}$

Table 6: Concentration (\%) of marker compound in EAE

\begin{tabular}{lc}
\hline Marker & Concentration (\%) in EAE \\
\hline Lupeol & 0.0168 \\
\hline
\end{tabular}

\section{Antimicrobial Activity}

The EAE was subjected for evaluation of the antibacterial and antifungal activity against Staphylococcus aureus (Gram-positive), Pseudomonas aeruginosa (Gram-negative) and Bacillus subtilis (Gram-positive) bacterial microorganisms and the fungi including Candida albicans, Aspergillus flavus and Epidermophyton floccosum ${ }^{18}$. For the determination of ZOI, ciprofloxacin (antibacterial) and fluconazole (antifungal) were taken as standards ${ }^{19}$. The ZOI against the bacterial and fungal strains is tabulated in Table 7 and presented in Fig. 4. The results are expressed as diameters of $\mathrm{ZOI}$ in $\mathrm{mm}$ (mean $\pm S D ; n=3)$. The $Z O I$ was found to be $37 \pm 1.29$ $\mathrm{mm}, 41 \pm 1.26 \mathrm{~mm}$ and $24 \pm 1.81 \mathrm{~mm}$ against Staphylococcus aureus, Pseudomonas aeruginosa and Bacillus subtilis respectively and for antifungal activity $13 \pm 1.22 \mathrm{~mm}, 16 \pm 1.26 \mathrm{~mm}$ and $11 \pm 1.02 \mathrm{~mm}$ against Candida albicans, Aspergillus flavus and Epidermophyton floccosum respectively at $1000 \mu \mathrm{g} /$ $\mathrm{mL}$ concentration. On the basis of ZOI (mean), it was noticed that Betula alnoides bark extract possess antibacterial and antifungal activity in a concentration dependent fashion. The findings of present study concluded that EAE is capable to exhibit significant antimicrobial activity, when compared with standard drug ciprofloxacin and fluconazole.

Table 7: Antimicrobial screening test of EAE against some bacterial and fungal strains

\begin{tabular}{|c|c|c|c|c|c|c|}
\hline \multirow[t]{2}{*}{ Drug/Extract (Concentration in $\mu \mathrm{g} / \mathrm{mL}$ ) } & \multicolumn{6}{|c|}{$\mathrm{ZOI}$ in $\mathrm{mm}(\mathrm{n}=3)$} \\
\hline & $\mathrm{Sa}$ & $\mathrm{Pa}$ & Bs & $\mathrm{Ca}$ & Af & Ef \\
\hline Ciprofloxacin(30) & $40 \pm 1.20$ & $45 \pm 1.84$ & $28 \pm 1.28$ & - & - & - \\
\hline Fluconazole(25) & - & - & - & $15 \pm 1.05$ & $17 \pm 1.84$ & $12 \pm 0.92$ \\
\hline EAE 50 & $4 \pm 1.42$ & $6 \pm 1.62$ & $3 \pm 1.42$ & $4 \pm 1.40$ & $5 \pm 1.62$ & $4 \pm 1.02$ \\
\hline EAE 100 & $9 \pm 1.62$ & $10 \pm 1.92$ & $6 \pm 1.80$ & $6 \pm 1.01$ & $8 \pm 1.92$ & $7 \pm 0.84$ \\
\hline EAE 250 & $18 \pm 1.22$ & $20 \pm 1.88$ & $15 \pm 1.34$ & $9 \pm 1.32$ & $11 \pm 1.88$ & $9 \pm 0.92$ \\
\hline EAE 500 & $25 \pm 1.37$ & $29 \pm 1.64$ & $19 \pm 1.21$ & $10 \pm 1.30$ & $13 \pm 1.64$ & $10 \pm 0.90$ \\
\hline EAE 1000 & $37 \pm 1.29$ & $41 \pm 1.26$ & $24 \pm 1.81$ & $13 \pm 1.22$ & $16 \pm 1.26$ & $11 \pm 1.02$ \\
\hline
\end{tabular}

Sa: Staphylococcus aureus, Pa: Pseudomonas aeruginosa, Bs: Bacillus subtilis, Ca: Candida albicans, Af: Aspergillus flavus, Ef: Epidermophyton floccosum. Data are means of three replicates $(n=3) \pm$ standard error

The MIC is the minimum concentration of any antimicrobial agent which is bacteriostatic in nature. MIC is employed to assess the growth of bacteria prevented. The antimicrobial efficacy of the extract was evaluated by $\mathrm{MIC}^{20}$. The lowest concentration of an antibacterial agent that kills $99.9 \%$ of the bacterial drug inoculum over an extended period of time, under some specific lab conditions is known as $\mathrm{MBC}^{21}$. Finding of MIC and $\mathrm{MBC}$ of EAE is presented in Table 8. Results showed that MIC values were $310 \mu \mathrm{g} / \mathrm{mL}, 140 \mu \mathrm{g} /$ $\mathrm{mL}$, and $220 \mu \mathrm{g} / \mathrm{mL}$, MBC values were $2000 \mu \mathrm{g} /$ $\mathrm{mL}, 1260 \mu \mathrm{g} / \mathrm{mL}$ and $1898 \mu \mathrm{g} / \mathrm{mL}$ and Equivalent ratio of $\mathrm{MBC} / \mathrm{MIC}$ was found to be $6.5,9.0$ and 8.6 for Staphylococcus aureus, Pseudomonas aeruginosa and Bacillus subtilis respectively. For fungal strains, the MIC values were $120 \mu \mathrm{g} / \mathrm{mL}$, $60 \mu \mathrm{g} / \mathrm{mL}, 128 \mu \mathrm{g} / \mathrm{mL}$ and MBC values were 440 
$\mu \mathrm{g} / \mathrm{mL}, 168 \mu \mathrm{g} / \mathrm{mL}, 467 \mu \mathrm{g} / \mathrm{mL}$ with equivalent ratio of MBC/MIC of 3.6, 2.8, 3.6 for Candida albicans, Aspergillus flavus and Epidermophyton floccosum respectively. Previous researchers have reported that, if the ratio of $\mathrm{MBC} / \mathrm{MIC}$ is lower than or equal to 4 , the test material may be considered bactericidal/fungicidal; in contrast, if this ratio is higher than 4 , the extract is considered bacteriostatic/fungistatic ${ }^{22}$. In present study, the $\mathrm{MBC} / \mathrm{MIC}$ ratio was more than 4 for bacterial strains and less than 4 for tested fungal strains. Therefore, it can be concluded that the tested plant extract $(E A E)$ is bacteriostatic and fungicidal in nature. The phytochemical study revealed the presence of the significant amount of triterpenoids. In a previous study, triterpenoids are proven agents for antimicrobial action. Therefore triterpenoids (secondary metabolite) present in the EAE may be responsible for the antimicrobial action.

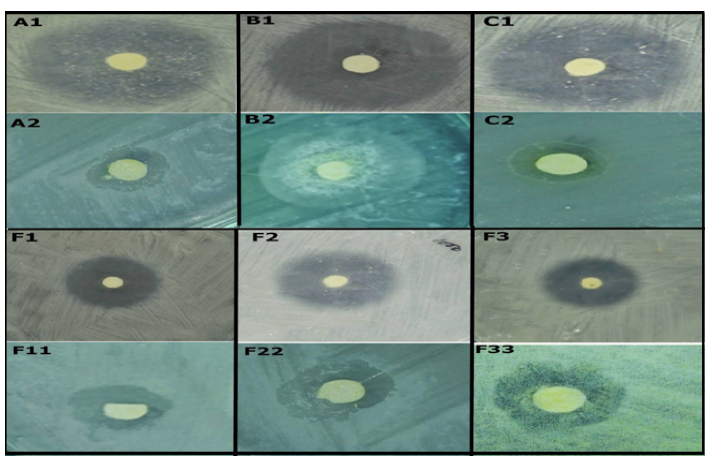

Antibacterial-A1: Ciprofloxacin against Staphylococcus aureus, B1: Ciprofloxacin against Pseudomonas aeruginosa, C1: Ciprofloxacin against Bacillus subtilis; EAE (1000 $\mu \mathrm{g} /$ ml) extract A2: against Staphylococcus aureus, B2: against Pseudomonas aeruginosa and C2: against Bacillus subtilis Antifungal-F1: Fluconazole against Candida albicans, F2: Fluconazole against Aspergillus flavus, F3: Fluconazole against Epidermophyton floccosum; EAE (1000 $\mu \mathrm{g} / \mathrm{ml})$ extract F11: against Candida albicans, F22: against Aspergillus flavus and F33: against Epidermophyton floccosum

Fig. 4. Inhibition effect of EAE of Betula alnoides bark against the micro-organisms in disk-diffusion method
Table 8: MIC and MBC of EAE of Betula alnoides bark Bacterial Strains

\begin{tabular}{lccc}
\hline & $\mathrm{MIC}(\mu \mathrm{g} / \mathrm{mL})$ & $\mathrm{MBC}(\mu \mathrm{g} / \mathrm{mL})$ & $\mathrm{MBC} / \mathrm{MIC}$ \\
\hline S. aureus & 310 & 2000 & 6.5 \\
P. aeruginosa & 140 & 1264 & 9.0 \\
B. subtilis & 220 & 1898 & 8.6 \\
Fungal Strains & & & \\
C. albicans & 120 & 440 & 3.6 \\
A. flavus & 60 & 168 & 2.8 \\
E. floccosum & 128 & 467 & 3.6 \\
\hline
\end{tabular}

\section{CONCLUSION}

The developed HPTLC method provided reproducible results, accurate and précised findings. The chromatogram of lupeol and EAE by direct band comparison clearly confirmed the presence of lupeol in the solvent system used in the analysis. An accurate HPTLC method was developed for the first time for the purpose of lupeol isolation. The proposed and validated method may be used for the quantification of lupeol from other extract also. The significant antimicrobial activity may be due to the presence of a triterpenoid (lupeol) as the EAE possesses antimicrobial potential. In the present study, antimicrobial evaluation of EAE of Betula alnoides bark was performed. As per the traditional claim mentioned in Ayurvedic literature, Betula alnoides bark is used to treat various ailments including sepsis. Using the In vitro antimicrobial scientific model, EAE of Betula alnoides bark was found to have potential to prevent the growth of Gram (+) and Gram (-) bacteria strains in dose-dependent manner. It was concluded that it may be used to treat the bacterial and fungal-related problems.

\section{ACKNOWLEDGMENT}

The present work is the part of $\mathrm{PhD}$ degree from IFTM University, Moradabad. Authors wish to thanks, management of IFTM University for assistance.

\section{Conflicts of Interest}

The authors declare no conflict of interest.

\section{REFERENCES}

1. Riaz, T.; Abbasi, M. A.; Aziz-ur-Rehman, S. T.; Ajaib, M.; Khan, K. M. J. Serb. Chem. Soc., 2012, 77(4), 423-435.

2. Gull, T.; Sultana, B.; Bhatti, I. A.; Jamil, A. Int. J. Agric. Biol., 2015, 1814-9596.

3. Ramzi, A.; Mothana, A.; Salah, A.; Abdo, A.; Sidgi, H.; Faisal, M.; Althawab, N.; Sama, A.;
Alaghbari, Z.; Ulrike, L. Adv. Acc. Pub., 2010, 7(3), 323-330.

4. Phan, MG.; Truong, T.T.C.; Phan, T.S.; Matsunami, O.H. Three new dammarane glycosides from Betula alnoides. Phytochem Lett., 2011, 4(2), 179-182. 
5. Mali, R.G.; Cleome viscosa (wild mustard): A review on ethnobotany, phytochemistry, and pharmacology. Pharm. Biol., 2010, 48(1), 105-112.

6. Chandra, M. Antimicrobial activity of medicinal plants against human pathogenic bacteria. Intern. J. Biotechnol. Biochem., 2013, 4(7), 653-8.

7. Salvi, ND.; George, L.; Eapen, S. Plant regeneration from leaf base callus of turmeric and random amplified polymorphic DNA analysis of regenerated plants. P. Cell. Tissue. Organ. Cult., 2001, 66(2), 113-9.

8. Sakkas, H.; Gousia, P.; Economou, V.; Sakkas, V.; Petsios, S.; Papadopoulou, C. In vitro antimicrobial activity of five essential oils on multidrug resistant Gram-negative clinical isolates. J. Intercult. Ethnopharmacol., 2016, 5(3), 212

9. Khan, Z.S.; Khuroo, A.A.; Dar, G.H. Ethnomedicinal survey of Uri, Kashmir Himalaya.; Indian J. Trad. Knowl., 2004, 3, 351-357.

10. Pandeya, D.K.; Radha, Dey A.; A validated and densitometric HPTLC method for the simultaneous quantification of reserpine and ajmalicine in Rauvolfia serpentina and Rauvolfia tetraphylla. Rev Bras de Farmacog., 2016, 26, 553-557.

11. Shah, M.B.; Patel, A.A.; Amin, A.A.; Patwari, A.H. Validated high performance thin layer chromatography method for simultaneous determination of quercetin and gallic acid in Leea indica. Rev. Bras. De. Farmacog., 2017, 27, 50-53.

12. Mukherjee, D.; Kumar, N.S.; Khatua, T.; Mukherjee, P.K.; Rapid validated method for estimation of betulinic acid in Nelumbo nucifera (Nymphacaeae). Phytochem. Anal., 2010, 21(6), 556-560.

13. Qin, W.; He, Y.; Xiao, J.; Liang, S.; Wang S.; Li, P.C.; Sun Y. A successive laminar flow extraction for plant medicine preparation by microfluidic chip. Microfluid. Nanofluidics.,
2019, 23(4), 1-8.

14. Kumar, A; Mishra, A.; Mishra, A.K; Singh, H. Quantification of the secondary metabolites by HPTLC, analgesic and antipyretic activity evaluation of Ficus racemosa L. leaves. Orient. Pharm. Exp. Med., 2019, 3,19(1), 59-69.

15. Razmavar, S.; Abdulla, M.A.; Ismail, S.B.; Hassandarvish, P. Antibacterial activity of leaf extracts of Baeckea frutescens against methicillin-resistant Staphylococcus aureus. Biomed. Res. Int., 2014, 6(16), 1-5.

16. Balouiri, M.; Sadiki, M.; Ibnsouda, S.K.; Methods for in vitro evaluating antimicrobial activity: A review. Journal of pharmaceutical analysis., 2016, 1, 6(2), 71-9.

17. Ormerod, L.D.; Paton, B.G.; Haaf, J.; Topping, T.M.; Baker, A.S.; Anaerobic bacterial endophthalmitis. Ophthalmology., 1987, 1,94(7), 799-808.

18. Akinsulire, O.R.; Aibin, I.E.; Adenipekun, T.; Adelowotan, T.; Odugbemi, T. In vitro antimicrobial activity of crude extracts from plants Bryophyllum pinnatum and Kalanchoe crenata. African Journal of Traditional, Complementary and Alternative Medicines., 2007, 4(3), 338-44.

19. Pradhan, R.R.; Hati, D.K.; Samal, S. Pharmacognostical, phytochemical and antimicrobial studies on the leaves of Lantana camara Linn. Der Pharmacia Lettre., 2012, 4, (6), 1648-56.

20. Mostafa, A.A.; Al-Askar, A.A.; Almaary, K.S.; Dawoud, T.M.; Sholkamy, E.N.; Bakri, M.M. Antimicrobial activity of some plant extracts against bacterial strains causing food poisoning diseases. Saudi Journal of Biological Sciences., 2018, 1,25(2), 361-6.

21. Vogelman, B.; Craig, W.A. Kinetics of antimicrobial activity. The Journal of pediatrics. 1986, 1,108(5), 835-40.

22. Bhalodia, N.R.; Shukla, V.J. Antibacterial and antifungal activities from leaf extracts of Cassia fistula: An ethnomedicinal plant. J. Adv. Pharma. Technol. \& Res., 2011, 2(2), 104. 